\title{
Comparação teórico-experimental do comportamento de vigas de concreto armado com fibras de aço
}

Uma alternativa para aumentar a resistência e o desempenho do concreto pode ser obtido com adição de fibras. Assim, a pesquisa é dada pelo estudo teóricoexperimental de fibras de aço em relação ao seu comportamento mecânico perante aos esforços de flexão, resistência a compressão, resistência a tração na compressão diametral e resistência a tração na flexão, em elementos estruturais, especificamente em vigas feitas com concreto armado. A intenção é que os métodos analíticos possam ser uma alternativa como substituição parcial ou total de alguns ensaios mecânicos, o que trará enorme vantagem de ordem prática. Portanto, comparou-se os resultados experimentais obtidos por pesquisadores com os métodos analíticos disponibilizados em literatura. Verificou-se que é necessário que ocorra aperfeiçoamento nos métodos de análise, levando em consideração todos os parâmetros existentes, permitindo uma coerência entre os valores experimentais e teóricos.

Palavras-chave: Viga de concreto; Fibra de aço; Concreto com fibras; Análise teórica.

\section{Theoretical-experimental comparison of the behavior of steel fiber reinforced concrete beams}

\begin{abstract}
An alternative to increase stamina and performance of concrete can be achieved by adding fibers. So, the research is given by the theoretical and experimenta study of steel fibers in relation to your mechanical behavior before bending efforts, resistance to compression, diametral tensile strength in compression and tensile strength in bending, structural elements, specifically in girders made of reinforced concrete. The intention is that the analytical methods may be an alternative as partial or total replacement of some mechanical tests, which will bring huge practical advantage. Therefore, compared the experimental results obtained by researchers with the analytical methods available in literature. It was found that is necessary for processing occurs in the methods of analysis, taking into account all existing parameters, allowing consistency between the experimental and theoretical values.
\end{abstract}

Keywords: Concrete beam; Steel fiber; Fiber reinforced concrete; Theorical analyses.

Topic: Sustentabilidade nos Transportes

Reviewed anonymously in the process of blind peer.
Received: $10 / 06 / 2018$

Approved: 24/07/2018
Marina Donato id

Instituto Militar de Engenharia, Brasil

http://lattes.cnpq.br/3065688209469583

http://orcid.org/0000-0002-9792-0940

marina_donato_eng.civil@yahoo.com.br

Ana Maria Abreu Jorge Teixeira (iD)

Instituto Militar de Engenharia, Brasil

http://lattes.cnpq.br/1454254574734029

http://orcid.org/0000-0003-3762-7192

donato@ime.eb.br

Luiz Antonio Vieira Carneiro

Universidade Federal Fluminense, Brasil

http://lattes.cnpq.br/2431901858566512

donato@ime.eb.br
Referencing this:

DONATO, M.; TEIXEIRA, A. M. A. J.; CARNEIRO, L. A. V.. Comparação teórico-experimental do comportamento de vigas de concreto armado com fibras de aço. Revista Ibero Americana de Ciências Ambientais, v.9, n.5, p.117-132, 2018. DOI: http://doi.org/10.6008/CBPC21796858.2018.005.0012 


\section{INTRODUÇÃO}

Materiais cimentícios, como o concreto, têm uma baixa capacidade de suportar esforços de tração, porém uma forma de diminuir essa deficiência é a inserção de armaduras, que são responsáveis por absorver esforços que a matriz não é capaz de absorver (BENTUR et al., 2007; FIGUEIREDO, 2000). É comumente utilizado para determinadas aplicações o concreto com reforços contínuos (barras de aço) e descontínuos (fibras), sendo a armadura de aço mais tradicional (BENTUR et al., 2007; ACI 544. 1R-96, 2002; SALVADOR, 2013).

Uma alternativa para aumentar a resistência e o desempenho do concreto pode ser obtido com adição de fibras. O concreto com fibras é aquele que em sua composição inclui fibras discretas e aleatoriamente distribuídas. A mistura deste material é constituída por cimento, água, agregados miúdos e graúdos e fibras, podendo ter aditivos químicos e adições minerais para melhorar a resistência mecânica e trabalhabilidade.

Alguns autores apontam que não há restrições quanto ao tipo de cimento a ser utilizado, este deve estar de acordo com a utilização do concreto com fibras e a resistência requerida (BALAGURU, 1992; OLIVEIRA, 2005). Os agregados são os mesmos utilizados no concreto convencional, porém a dimensão máxima é de grande importância, de forma que ocorra compatibilidade com as fibras (OLIVEIRA, 2005). A quantidade de fibras utilizada na mistura cimentícia é pequena em relação ao volume de concreto, variando de 1 a 5\% (NEVILLE et al., 2013).

A incorporação de fibras em misturas cimentícias promove uma melhora significativa em diversas propriedades mecânicas da matriz, podendo destacar o aumento da ductilidade e controle da fissuração nas estruturas. Observa-se que a fissuração é um dos maiores problemas para as estruturas de concreto armado, pois esse tipo de patologia tende a criar aberturas na estrutura de forma a favorecer o ataque de agentes agressivos.

De acordo com Figueiredo (2011), a pesquisa sobre o concreto reforçado com fibras no mundo é destaque na Europa e Estados Unidos da América. Sendo uma realidade distinta do Brasil, ressaltando pelas normalizações estabelecidas. A utilização do concreto com fibras no Brasil é descrita como uma atividade basicamente empírica, pois são utilizados teores de fibras fixo e total ausência de controle da qualidade do compósito. As aplicações das fibras estão associadas a obras de infraestrutura, notadamente as de saneamento básico e de transporte (ALBERTI et al., 2014).

As principais fibras dispersas estudadas e utilizadas no mercado, com intuito de serem adicionadas no concreto são as fibras de aço. As fibras metálicas, principalmente as de aço, são comumente empregadas em elementos estruturais de concreto, pois devido ao seu alto módulo de elasticidade melhoram características como tenacidade, controle de fissuras, resistência à flexão, resistência ao impacto e à fadiga (ACI 544. 1R-96, 2002).

O desempenho final do concreto com fibras depende da combinação das propriedades mecânicas e físicas da matriz e da fibra (NAAMAN, 2007). Grandes avanços nas pesquisas e aplicações dos concretos com 
fibras ocorreram nas últimas décadas. A utilização desse material é cada vez maior em todo o mundo e hoje existem vários tipos de fibras disponíveis no mercado.

Atualmente, as fibras mais utilizadas no concreto no mercado são as fibras de aço, pois apresentam ampla disponibilidade e elevadas propriedades de resistência (ALBERTI et al., 2014). No Brasil diversos estudos foram publicados sobre a investigação do comportamento de fibras de aço em matrizes de concreto. Sua utilização já está amplamente difundida no mercado brasileiro, que apresenta vasta gama de produtores e distribuidores (SALVADOR, 2013). O crescente avanço das pesquisas sobre as propriedades do concreto com fibras possibilita a entrada de novas tecnologias e materiais.

Cada tipo de fibra contribui diferentemente com a melhoria das propriedades do concreto. Desta forma, justifica-se o estudo deste trabalho, procurando entender as suas características e como essas contribuem para melhorar a resistência do concreto. Como enfatizado, o interesse do estudo recai sobre as fibras aço.

Por estas razões, a utilização de fibras como reforço em vigas de concreto armado é para ajudar a estrutura a suportar as diversas solicitações decorrentes de carregamentos uniaxiais, biaxiais, fadiga, compressão ou causados pelo vento, vibrações de máquinas, veículos ou terremotos. Além disso, no Brasil ainda não foi publicada norma especifica para avaliar o comportamento mecânico de fibras. Portanto, esta pesquisa pode servir como literatura base para a elaboração de um procedimento normatizado no mercado brasileiro.

Portanto, a proposta deste trabalho é dada pelo estudo teórico - experimental das fibras de aço em relação ao seu comportamento mecânico perante aos esforços de flexão, resistência a compressão, resistência a tração na compressão diametral e resistência a tração na flexão, em elementos estruturais, especificamente em vigas feitas com concreto armado.

\section{REVISÃO TEÓRICA}

Furlan Jr. et al. (1997), apresentam uma pesquisa que retrata a análise de cisalhamento em vigas de concreto com fibra de aço e polipropileno. As vigas de concreto foram preparadas a partir de sete proporções de mistura diferentes, variando o tipo e o volume de fibra adicionado. Uma das sete misturas de concreto não contém fibra. No total o autor preparou dois tipos de vigas para cada tipo de mistura, sendo a única variação o reforço de cisalhamento: um com estribos (vigas da série A) e um sem estribos (vigas da série B), conforme mostrado na Tabela 1. Portanto, variando a armadura e o tipo de fibra, foram preparadas 14 vigas de concreto de seção quadrada (100 x $100 \times 1000$ mm). A Tabela 1 resume as variações das vigas de concreto.

Tabela 1: Características das vigas de concreto.

\begin{tabular}{|l|l|l|l|}
\hline Vigas & Tipo de fibra & Volume de fibra (\%) & Resistência do concreto (MPa) \\
\hline V.1. A /V.1. B & - & - & 43,8 \\
\hline V.2. A /V.2. B & Polipropileno & 0,5 & 48,0 \\
\hline V.3. A /V.3. B & Aço $25,4 \mathrm{~mm}$ & 1,0 & 54,8 \\
\hline V.4. A / V.4. B & Aço $25,4 \mathrm{~mm}$ & 2,0 & 50,0 \\
\hline V.5. A /V.5. B & Aço $38,1 \mathrm{~mm}$ & 1,0 & 49,3 \\
\hline V.6. A /V.6. B & Aço $38,1 \mathrm{~mm}$ & 2,0 & 53,7 \\
\hline V.7. A /V.7. B & Aço $38,1 \mathrm{~mm}$ & 0,5 & 53,5 \\
\hline
\end{tabular}

Fonte: Furlan Júnior et al. (1997). 

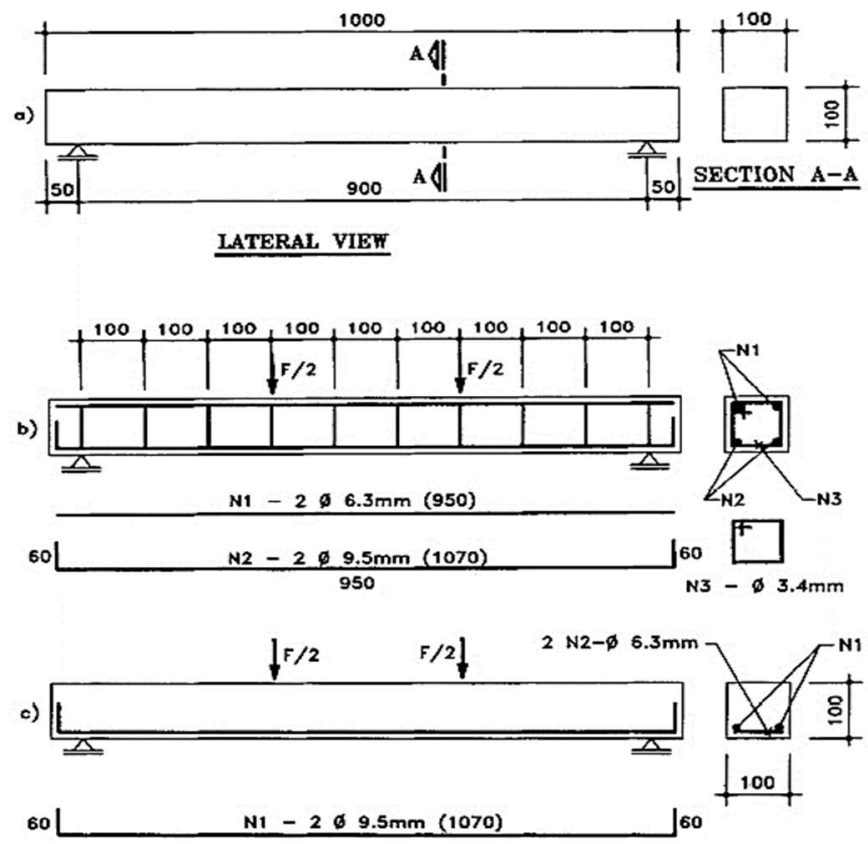

Figura 1: Vigas armadas (a) Geometria; (b) Armadura de vigas de seção A; (c) Armadura de vigas de seção B.

Fonte: Furlan Jr. et al. (1997).

As vigas foram testadas aplicando duas cargas pontuais nos terços do intervalo. A relação entre a distância das cargas aos suportes e a altura efetiva das vigas foi igual a 3,5. A instrumentação foi realizada com medidores de tensão elétrica na zona de compressão de concreto, no reforço longitudinal e nos estribos. Além disso, os medidores LVDT foram instalados nos suportes e no meio do span, para medir as deflexões do feixe (FURLAN et al., 1997).

Simultaneamente à preparação das vigas, foram moldadas quatro amostras cilíndricas de concreto de $(150 \times 300) \mathrm{mm}^{2}$ para determinar as propriedades mecânicas (FURLAN et al., 1997). As principais alterações resultantes do uso de fibras foram o aumento da resistência ao cisalhamento, rigidez (particularmente após o primeiro estágio de fissuração) e ductilidade (FURLAN et al., 1997).

Segundo Lobão (2005), a utilização de fibras metálicas em elementos estruturais pode trazer algumas vantagens, entre as quais o aumento de ductilidade dos mesmos. O autor ensaiou quatro vigas de seção retangular variando a taxa de armadura longitudinal de tração, conforme a Tabela 2. Essas vigas foram denominadas $\mathrm{V}-\mathrm{R}, \mathrm{V}-1, \mathrm{~V}-2$ e $\mathrm{V}-3$. Todas as vigas foram bi-apoiadas e carregadas com uma carga no meio do vão até sua ruptura.

A viga V-R, a de referência, não possui armaduras transversal e longitudinal. Nas vigas armadas utilizaram-se estribos de barras de aço de diâmetro 5,0 $\mathrm{mm}$ a cada $150 \mathrm{~mm}$, garantindo, assim, que a ruptura não ocorreria por cortante, mas por flexão. A armadura longitudinal de tração da viga $V-1$ foi composta por duas barras de aço CA-60 com diâmetro de 5,0 mm. Nas vigas V-2 e V-3 usaram-se barras de aço CA-50 com diâmetro de 6,3 mm; duas e três respectivamente, conforme a Figura 2 (LOBÃO, 2005).

As quatro vigas possuem comprimento de $3200 \mathrm{~mm}$ e seção transversal retangular de $150 \mathrm{~mm} \times 300$ $\mathrm{mm}$. As vigas bi-apoiadas, com $3000 \mathrm{~mm}$ de distância entre os centros dos apoios, sendo um apoio do 1은 gênero e o outro do 2 o gênero. $O$ carregamento das vigas consistiu de uma carga concentrada aplicadas no meio do vão, onde é desconsiderado o peso próprio da viga (LOBÃO, 2005). Para cada viga foram moldados 
cinco corpos de prova cilíndricos de $150 \mathrm{~mm}$ x $300 \mathrm{~mm}$. Os ensaios realizados nos corpos de provas foram de resistência à compressão e de resistência à tração (compressão diametral) (LOBÃO, 2005).

Tabela 2: Características das vigas de concreto.

\begin{tabular}{|l|l|l|l|}
\hline Vigas & Tipo de fibra & Volume de fibra (\%) & Resistência do concreto (MPa) \\
\hline V.R & - & - & 35,6 \\
\hline V.1 & Aço & 0,38 & 26,1 \\
\hline V.2 & Aço & 0,38 & 32,3 \\
\hline V. 3 & Aço & 0,38 & 42,6 \\
\hline
\end{tabular}

Fonte: Lobão (2005).
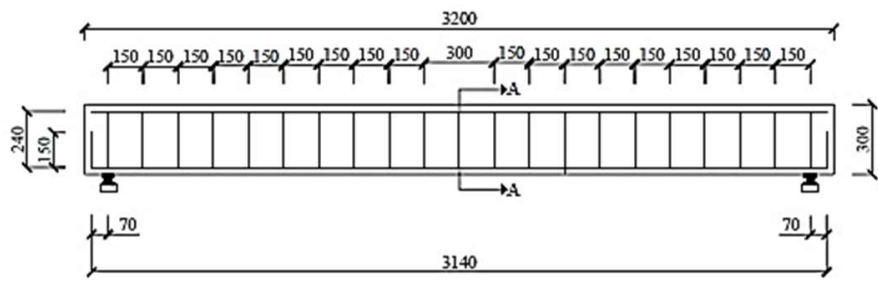

CORTE A-A

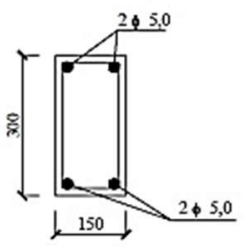

V-1

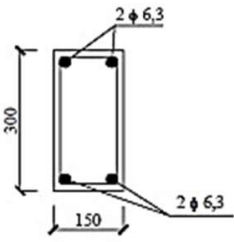

$\mathrm{V}-2$

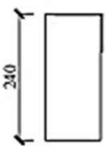

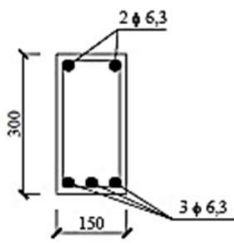

V-3

Figura 1: Detalhamento das armaduras longitudinal e transversal da V-1, V-2 e V-3. Fonte: Lobão (2005).

Oliveira (2005), abordou em sua pesquisa o comportamento de vigas com baixa taxa de armadura longitudinal e os parâmetros que nele influem, e comparou os comportamentos de vigas sem e com fibras de aço. O autor ensaiou quatro vigas, variando a taxa de armadura de flexão, conforme a Tabela 3 . Essas vigas foram denominadas V-R, V-1, V-2 e V-3. As vigas tinham seção transversal retangular, foram simplesmente apoiadas e submetidas a uma carga concentrada no meio do vão.

As quatro vigas possuíam seção transversal retangular de $150 \mathrm{~mm}$ x $300 \mathrm{~mm}$ e comprimento total de 3200 mm. A viga V-R, a de referência, não possui armaduras transversal e longitudinal. O restante das vigas com armaduras longitudinal de tração e porta estribos das vigas foi usado aço CA-50 com diâmetro de 6,3 $\mathrm{mm}$. Para a armadura transversal foram utilizadas barras de CA-60 com diâmetro de 5,0 mm, conforme a Figura 3.

Todas as vigas foram bi-apoiadas em um apoio do 1ํ gênero e outro do 2o gênero, com os centros dos apoios distando $3000 \mathrm{~mm}$ entre si. O carregamento das vigas consistiu de uma carga concentrada aplicadas no meio do vão, onde é desconsiderado o peso próprio da viga Oliveira (2005). Para cada viga foram moldados cinco corpos de prova cilíndricos de $100 \mathrm{~mm}$ x $200 \mathrm{~mm}$. Os ensaios realizados nos corpos de provas foram de resistência à compressão e de resistência à tração (compressão diametral) Oliveira (2005). 
Tabela 3: Características das vigas de concreto.

\begin{tabular}{|l|l|l|l|}
\hline Vigas & Tipo de fibra & Volume de fibra (\%) & Resistência do concreto (MPa) \\
\hline V.R & - & - & 75,0 \\
\hline V.1 & Aço & 0,38 & 84,3 \\
\hline V.2 & Aço & 0,38 & 78,1 \\
\hline V.3 & Aço & 0,38 & 78,8 \\
\hline
\end{tabular}

Fonte: Oliveira (2005).
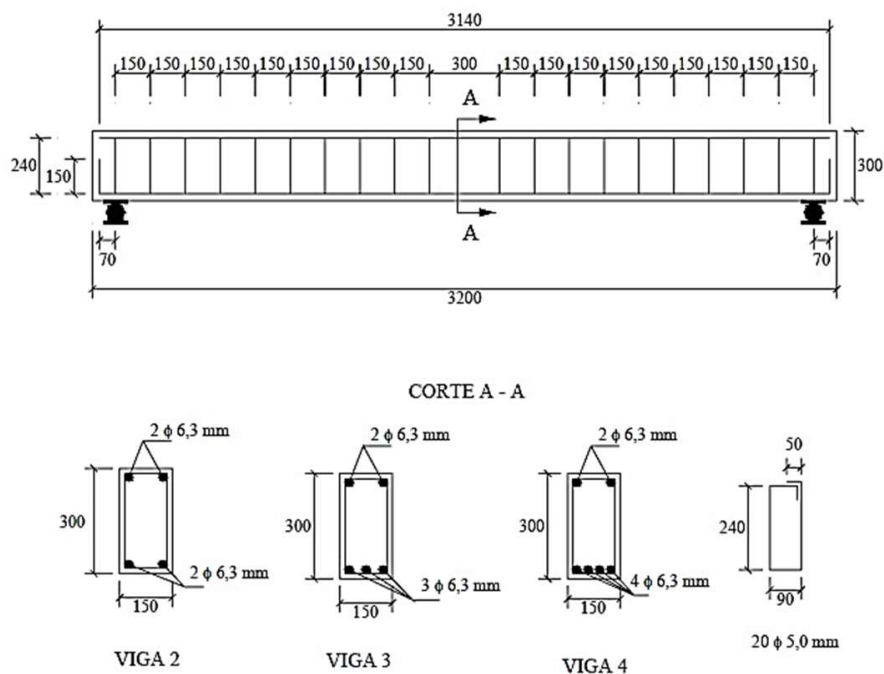

Figura 3: Detalhamento das armaduras longitudinal e transversal da v-1, v-2 e v-3. Fonte: Oliveira (2005).

Oliveira (2007), analisa em seu trabalho o comportamento à flexão de vigas de concreto armado reforçado com fibras de aço. Foram ensaiadas nove vigas de concreto armado com seção transversal de 200 $\mathrm{mm}$ x $600 \mathrm{~mm}$ e vão livre de $4000 \mathrm{~mm}$. Os volumes de fibras estudados foram 0,50\%, 0,75\%, 1,00\% e 1,25\%, e as fibras possuíam $60 \mathrm{~mm}$ de comprimento, conforme a Tabela 4.

O detalhamento da armadura das vigas é apresentado na Figura 4. Nessa figura, o item (a) se refere à armadura da viga V1, o item (b) se refere à armadura da viga V2, o item (c) se refere à armadura da viga V3, o item (d) se refere à armadura das vigas V4, V5 e V6 e o item (e) se refere à armadura das vigas V7, V8 e V9 (OLIVEIRA, 2007).

Para traços de concretos distintos foram moldados corpos de prova cilíndricos (150 x $300 \mathrm{~mm}$ ) para se determinar a resistência à compressão, módulo de elasticidade, resistência à tração por compressão diametral, tensão versus deformação na compressão, bem como corpos-de-prova prismáticos $(100 \times 100$ x $450 \mathrm{~mm}),(150 \times 150 \times 600 \mathrm{~mm})$ e $(200 \times 200 \times 800 \mathrm{~mm})$ para ensaios de flexão sob quatro pontos de força (OLIVEIRA, 2007).

Para Rodrigues Jr. (2009), os trabalhos desenvolvidos antes de 2009 se tratavam de estudos experimentais para investigar o comportamento à flexão de vigas de concreto com fibras abrangeu vigas com taxas de armadura longitudinal de tração maior que $1 \%$. O autor ensaiou cinco vigas de concreto com resistência à compressão da ordem de $45 \mathrm{MPa}$ e teores de fibras em volume de 0,382\%, 0,764\% e 1,15\%, e taxas de armadura longitudinal de tração de 0,238\% e 0,512\%. Para ajudar na identificação separou-se as vigas em três grupos distintos. O primeiro grupo, formado pelas vigas 1-2 e 1-3, possuía taxa de armadura longitudinal de tração de 0,238\% e teores de fibras de aço em volume de 0,764\% e 1,15\%. O segundo grupo, composto pelas vigas 2-1 2-2 e 2-3, possuía taxa de armadura longitudinal de tração de 0,512\% e teores de 
fibras de aço de 0,382\%, 0,764\% e 1,15\%. O terceiro grupo, composto somente da viga 1.1, são dados da viga ensaiada por Lobão (2005), pois possuía as características geométricas iguais às das vigas do autor e com taxas de armadura longitudinal e de volume de fibras de $0,238 \%$ e 0,382\%, respectivamente.

As seis vigas possuíam uma seção transversal retangular de $150 \mathrm{~mm} \times 300 \mathrm{~mm}$, altura útil de cerca de $262 \mathrm{~mm}$, comprimento de $3200 \mathrm{~mm}$ e vão de $3000 \mathrm{~mm}$. Todas as vigas foram bi-apoiadas em um aparelho de apoio do 1 으 gênero e outro do 2 o gênero e o carregamento consistiu em uma carga concentrada aplicada no centro do vão. A Tabela 5 apresenta as principais características das vigas (RODRIGUES Jr., 2009).

No primeiro e terceiro grupo de vigas (1-1, 1-2, 1-3), a armadura longitudinal de tração era 3 barras com diâmetro de 6,3 mm, próxima da mínima. No segundo grupo (2-1, 2-2, 2-3), a armadura longitudinal de tração era 4 barras com diâmetro de 8,0 mm, 2,15 vezes a das vigas do primeiro e terceiro grupo. Para a armadura longitudinal próxima da fibra mais comprimida adotaram-se duas barras com diâmetro igual ao das barras da armadura longitudinal de tração. As armaduras longitudinais e transversais podem ser vistas na Figura 5 (RODRIGUES Jr., 2009).

Tabela 4: Características das vigas de concreto.

\begin{tabular}{|l|l|l|l|}
\hline Vigas & Tipo de fibra & Volume de fibra (\%) & Resistência do concreto (MPa) \\
\hline V.1 & - & - & 46,9 \\
\hline V.2 & - & - & 41,6 \\
\hline V.3 & Aço & 0,75 & 52,7 \\
\hline V.4 & Aço & 0,75 & 44,9 \\
\hline V.5 & Aço & 1,00 & 54,3 \\
\hline V.6 & Aço & 1,25 & 66,2 \\
\hline V.7 & Aço & 0,50 & 55,3 \\
\hline V.8 & Aço & 0,75 & 53,3 \\
\hline V.9 & Aço & 1,25 & 62,3 \\
\hline
\end{tabular}

Fonte: Oliveira (2007).

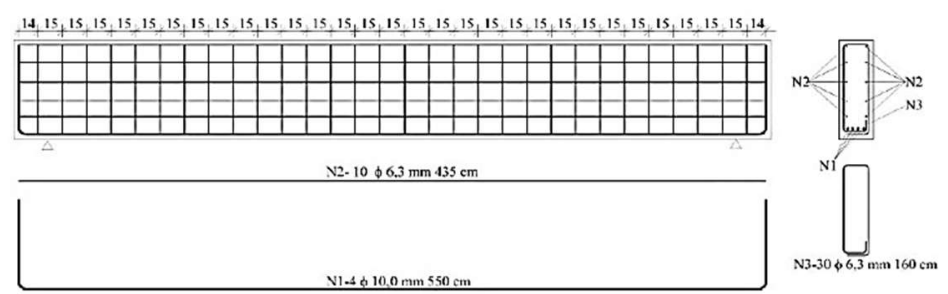

(a)
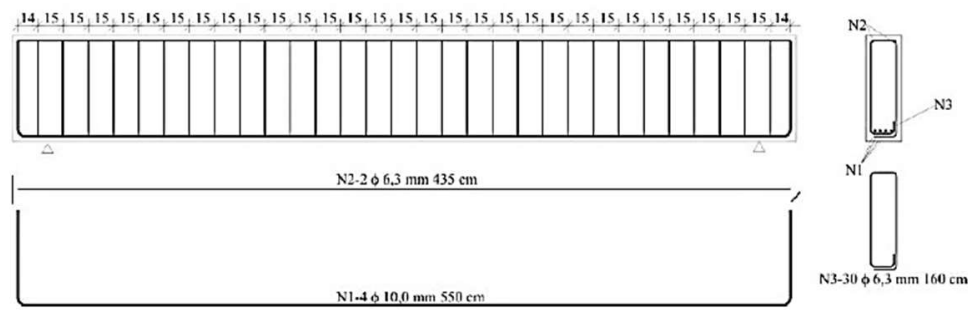

(b)
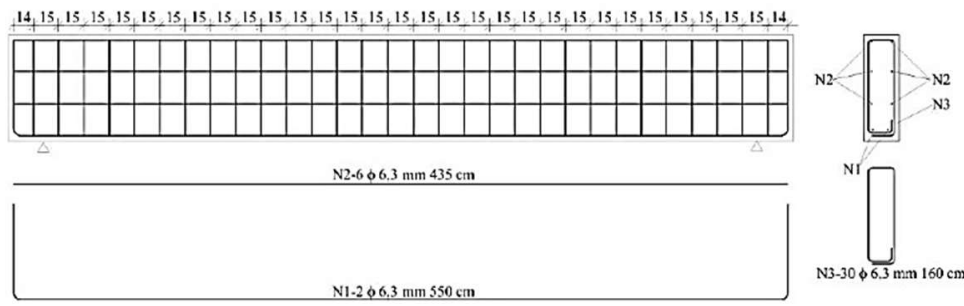

(c)

Figura 4: Detalhamento das armaduras longitudinal e transversal da V-1, V-2 e V-3. Fonte: Oliveira (2007). 
Tabela 5: Características das vigas de concreto.

\begin{tabular}{|l|l|l|l|}
\hline Vigas & Tipo de fibra & Volume de fibra (\%) & Resistência do concreto (MPa) \\
\hline V.1.1 & Aço & 0,38 & 42,6 \\
\hline V.1.2 & Aço & 0,76 & 46,1 \\
\hline V.1.3 & Aço & 1,15 & 46,0 \\
\hline V.2.1 & Aço & 0,38 & 45,9 \\
\hline V.2.2 & Aço & 0,76 & 46,1 \\
\hline V.2.3 & Aço & 1,15 & 46,0 \\
\hline
\end{tabular}

Fonte: Rodrigues Jr. (2009).

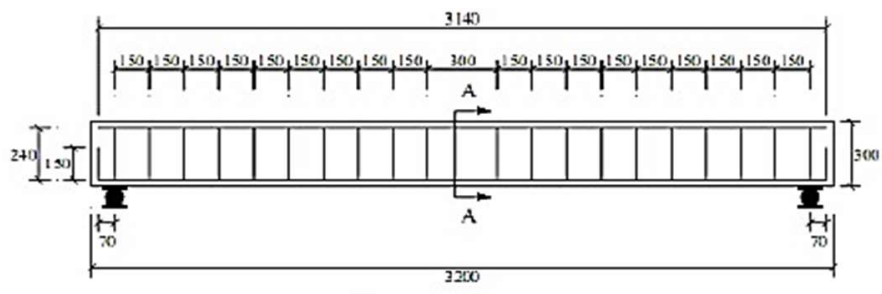

CORTE A-A

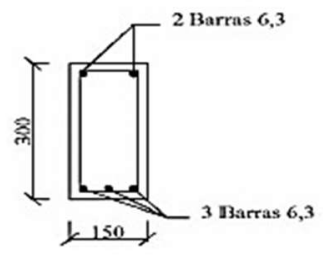

Vigas 1-1, 1-2 e 1-3

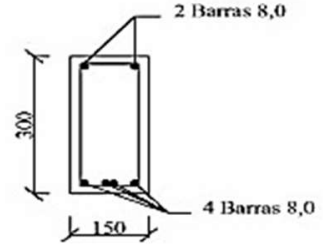

Vigas 2-1, 2-2 e 2-3

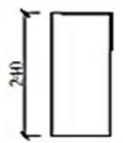

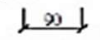

$20+1,0 \quad c=760$

Figura Erro! Nenhum texto com o estilo especificado foi encontrado no documento.2: Detalhamento das armaduras longitudinal e transversal. Fonte: Rodrigues Jr. (2009).

Foram ensaiados corpos de prova cilíndricos, de $(150 \times 300 \mathrm{~mm})$, para determinar a resistência à compressão, a resistência à tração por compressão diametral e a curva tensão normal de compressãodeformação específica. Três corpos de prova cilíndricos de cada tipo de concreto foram ensaiados à compressão (RODRIGUES Jr., 2009). Dois corpos de prova prismáticos (100 x 100 × 400 mm) de cada tipo de concreto foram inicialmente ensaiados com carga no meio do vão, obtendo-se para eles apenas a resistência, pois houve problema com o sistema para medição de deslocamento vertical no meio do vão (RODRIGUES Jr., 2009).

\section{Comparação teórico e experimental}

O comportamento do concreto com fibras à compressão é relativamente menos afetado pela presença de fibras, quando comparado com o comportamento sob tração e flexão (OLIVEIRA, 2005). Portanto, verificasse o desempenho de fibras dispersas no concreto a partir da comparação dos resultados de ensaios e equações disponibilizadas em literatura.

\section{Resistência a compressão do concreto}

A resistência à compressão é uma propriedade importante do concreto convencional, a adição de fibras no concreto produz um pequeno ou nenhum aumento na resistência à compressão do concreto 
(BENTUR et al., 2007). As fibras, incorporadas no concreto em teores normalmente menores que $2 \%$ em volume, nãos acrescentam melhoras substanciais na resistência a compressão do concreto (ACl 544. 2R-89, 2009). De acordo com ACl 544.1R-96 (2002), na compressão, a carga última é sensivelmente afetada pelo acréscimo de fibras ao concreto, onde são observados aumentos entre 0 e 15\% para frações volumétricas de fibras acima de 1,5\% em volume. Segundo o ACI 544.4R-88 (1999), as fibras com teores de fibras menores que $2 \%$ em volume não acrescentam melhoria na resistência à compressão do concreto.

Na Figura 6, observa-se a influência do teor de fibras no aumento da resistência e a relação de aspecto nas curvas tensão deformação do concreto com fibras de aço. Nota-se que em concretos com adição de fibras ocorre aumento significativo na deformação no pico da tensão de compressão e menor declive da parte descendente da curva sem fibras, ou seja, uma maior capacidade de absorver energia. Ressaltasse ainda que no comportamento pós pico os concretos com a adição de fibras, em termos de declividade do ramo descendente é mais suave, e levando-o a atingir níveis de deformação específica maiores, até a ruptura.

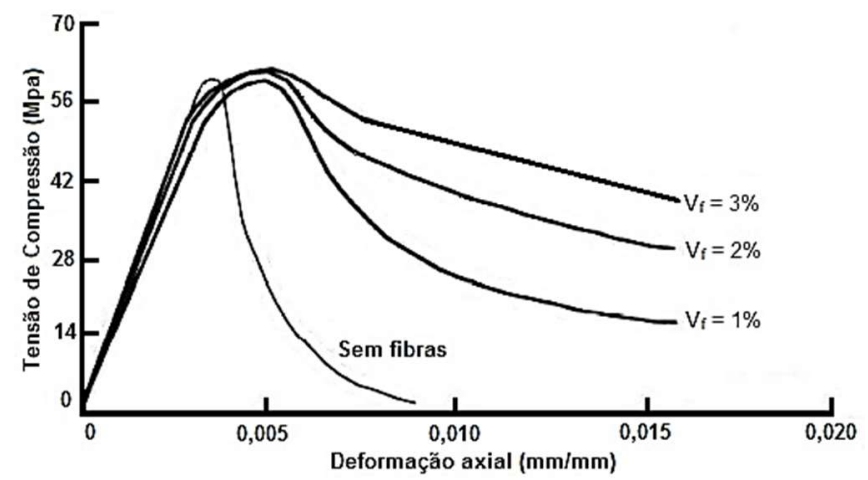

Figura 6: Influência no teor de fibras na curva tensão x deformação na compressão. Fonte: ACl 544. 4R-88 (1999).

Portanto, a adição das fibras em concretos não possui o intuito de promover aumento de resistência na estrutura, mas melhorar o comportamento pós-fissuração, permitindo assim que o concreto deforme bem mais quando tracionado. A Norma Brasileira NBR 5739 (2007) estabelece os parâmetros de ensaio dos corpos de prova submetidos a resistência a compressão. Os valores experimentais obtidos pelos autores, constam na Tabela 6.

Tabela 6: Valores experimentais da resistência a compressão axial de acordo com o volume de fibra.

\begin{tabular}{|c|c|c|c|c|}
\hline Autores & Vigas & $V_{f}(\%)$ & $f_{\mathrm{cm}}(\mathrm{MPa})$ & $f_{c m}(\%)$ \\
\hline \multirow[t]{6}{*}{ Furlan Jr., et al. (1997) } & V.1 & 0,00 & 43,8 & - \\
\hline & V.3 & 1,00 & 54,8 & 25,11 \\
\hline & V.4 & 2,00 & 50,0 & 14,15 \\
\hline & V.5 & 1,00 & 49,3 & 12,55 \\
\hline & V.6 & 2,00 & 53,7 & 22,60 \\
\hline & V.7 & 0,50 & 53,5 & 22,14 \\
\hline \multirow[t]{4}{*}{ Oliveira, 2005} & V.R & - & 75,0 & - \\
\hline & V.1 & 0,38 & 84,3 & 12,40 \\
\hline & V.2 & 0,38 & 78,1 & 4,13 \\
\hline & V.3 & 0,38 & 73,8 & 1,60 \\
\hline \multirow[t]{4}{*}{ Lobão, 2005} & V.R & - & 35,6 & - \\
\hline & V.1 & 0,38 & 26,1 & 26,68 \\
\hline & V.2 & 0,38 & 32,3 & 9,27 \\
\hline & V.3 & 0,38 & 42,6 & 19,66 \\
\hline \multirow[t]{2}{*}{ Oliveira, 2007} & V.1 & 0,00 & 46,9 & - \\
\hline & V.2 & 0,00 & 41,6 & - \\
\hline
\end{tabular}




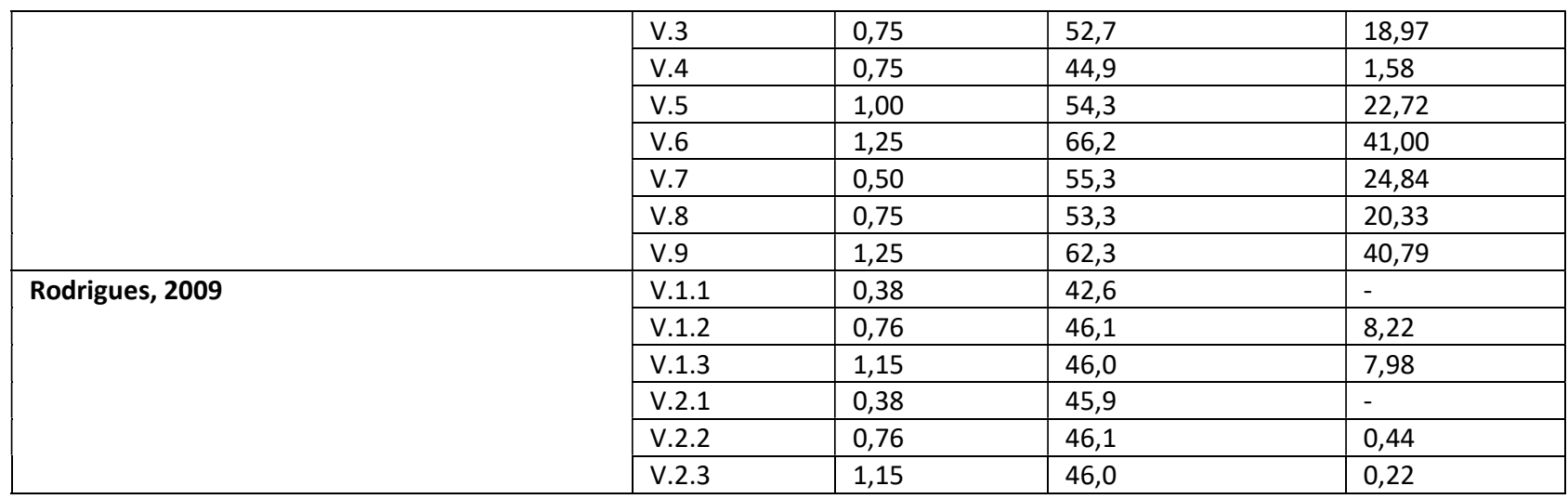

Os resultados listados na Tabela 6 mostram que a adição de fibras não contribuiu para um aumento significativo da resistência à compressão e que, quando houve aumento, esses tiveram comportamentos diferentes de acordo com cada autor.

\section{Resistência a tração na compressão diametral do concreto}

A adição de fibras em matrizes cimentícias podem melhorar a resistência à tração, que depende principalmente do volume de fibras utilizado. Contata-se que eficiência das fibras é menor do que a de barras de armadura, tratando-se em volume equivalente, são distribuídas e orientadas randomicamente, não estando alinhadas na direção das tensões solicitantes (LOPES, 2005).

Segundo a ACl 544.4R-88 (1999), a resistência à tração de concretos com fibras geralmente é da mesma ordem da dos concretos sem fibras (2 a $4 \mathrm{MPa}$ ). De acordo com Bentur et al. (2007), para que ocorra um aumento perceptível de resistência a tração no compósito faz se necessário adicionar teores elevados de fibras que possuem uma alta resistência a tração, deve-se a capacidade das fibras de manter uma parcela resistente mesmo após o aparecimento da primeira fissura no concreto. De acordo com ACl 544.1R-96 (2002), a fibra adicionada ao concreto a uma fração volumétrica de 1,5 \% observa-se incrementos entre 30 e $40 \%$ na resistência à tração direta de matrizes de concreto.

A resistência à tração é elevada se utilizadas fibras com alto módulo de elasticidade na mistura do concreto. Segundo Criswell (1994), citado por Lopes (2005), quando fibras de alto módulo de elasticidade são utilizadas, ocorre um aumento da resistência à tração, porém estas fibras comprometem a armadura tradicional ou substituam apenas uma parte dela. Para Lopes (2005), as fibras quando utilizadas corretamente com as armaduras convencionais no concreto, verifica-se uma contribuição na resistência à tração pós-fissuração, podendo ocorrer a diminuição na quantidade de armaduras, tanto de barras de aço usadas para resistir a esforços de flexão, quanto para estribos, utilizados para resistir ao cisalhamento [19].

Contudo, verifica-se que o tipo de fibras utilizadas no concreto não influencia significativamente a carga de fissuração do concreto com fibras (SHAH et al., 1976; citado por ZIA et al., 1994). A curva depende do tamanho e comprimento da estrutura, método de ensaio, rigidez da máquina de ensaio, e se única ou múltiplas fissuras ocorrem na estrutura (ACl 544. 4R-88, 1999).

O aumento da ductilidade à compressão do concreto com fibras é função, do tipo e da taxa volumétrica das fibras. Os altos índices de armadura $\left(\mathrm{V}_{\mathrm{f}} \mathrm{L}_{\mathrm{f}} / \mathrm{d}_{\mathrm{f}}\right)$ fazem com que o concreto apresente elevada 
ductilidade. A modelagem do comportamento tensão à compressão do concreto com fibras vem sendo investigada por alguns pesquisadores, pois esse modelo é necessário para a análise não linear de estruturas e serve de base para diagrama simplificado adotado em análise no estado limite último. Entretanto, devido às características específicas desse material, tais como o teor e o tipo das fibras de aço e a orientação das fibras na massa do concreto, a modelagem do comportamento se torna mais complexa do que a do concreto sem fibras. O modelo proposto por IMAM et al. (1995), resultou de uma pesquisa teórica que envolveu trabalhos de diversos pesquisadores sobre concretos com fibras de aço. A equação para o cálculo da resistência do concreto com fibras submetidos à tração por compressão diametral é expressa abaixo:

$$
f_{c t, s p}=0,80 f_{c}^{0,44}+\alpha I_{f}
$$

onde:

$\mathrm{f}_{\mathrm{c}}$ : Resistência do concreto à compressão sem fibra; $\alpha$ : Constante adimensional dependente do tipo de fibra, sendo igual a 1,0 para fibras com ganchos nas extremidades; If: fator dimensional dependente do fator de forma e do volume de fibras.

O valor de lf é dado pela Figura 8.

A partir dos dados coletados dos trabalhos dos ensaios de resistência à compressão diametral e calculados utilizando a equação 1, montou-se a Tabela 7. Em geral, a equação se mostrou satisfatória ao se comparar com os valores obtidos experimentalmente, pois os valores em sua maioria ficaram próximos a $100 \%$.

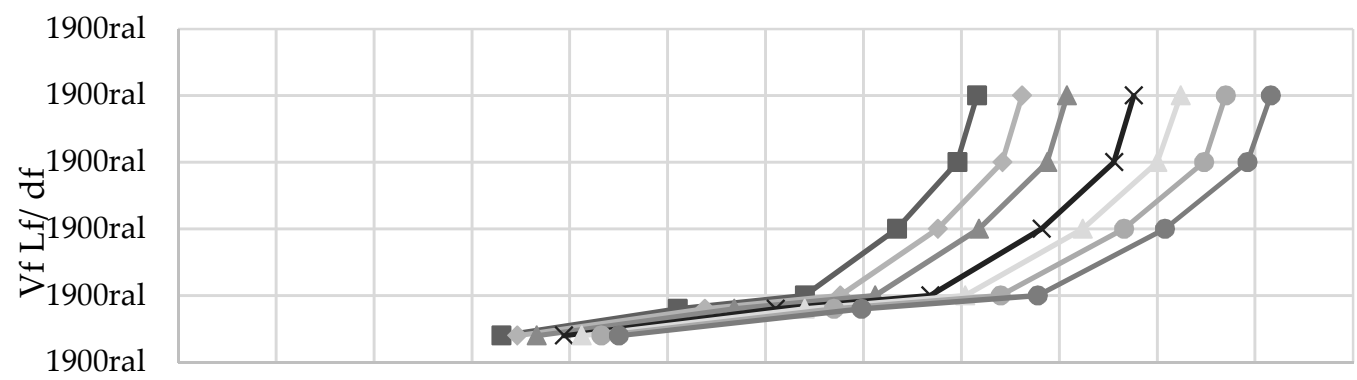

1900ral1900ral1900ral1900ral1900ral1900ral1900ral1900ral1900ral1900ral1900ral1900ral1900ral

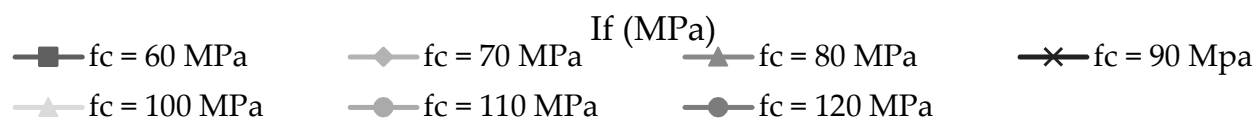

Figura 8: Gráfico dos valores do fator de fibra If. Fonte: IMAM et al. (1995).

Tabela 7: Valores experimentais e teóricos da resistência à compressão diametral.

\begin{tabular}{|c|c|c|c|c|c|c|}
\hline Autor & Vigas & $\mathrm{Vf}(\%)$ & $\mathrm{fcm}(\mathrm{MPa})$ & fct,sp (MPa) (Exp.) & fct,sp (MPa) (Calc.) & fct,sp (\%) \\
\hline \multirow[t]{6}{*}{ Furlan Jr., et al., 1997} & V.1 & 0,00 & 43,8 & 3,40 & 4,22 & 80,6 \\
\hline & V.3 & 1,00 & 54,8 & 3,30 & 7,01 & 47,1 \\
\hline & V.4 & 2,00 & 50,0 & 4,20 & 7,62 & 55,1 \\
\hline & V.5 & 1,00 & 49,3 & 3,85 & 6,67 & 57,8 \\
\hline & V.6 & 2,00 & 53,7 & 4,30 & 8,12 & 53,0 \\
\hline & V.7 & 0,50 & 53,5 & 3,60 & 6,31 & 57,1 \\
\hline \multirow[t]{4}{*}{ Oliveira, 2005} & V.R & - & 75,0 & 7,87 & 7,57 & 104,0 \\
\hline & V.1 & 0,38 & 84,3 & 7,83 & 8,00 & 97,9 \\
\hline & V.2 & 0,38 & 78,1 & 7,04 & 7,69 & 91,5 \\
\hline & V.3 & 0,38 & 73,8 & 6,27 & 7,51 & 83,5 \\
\hline \multirow[t]{4}{*}{ Lobão, 2005} & V.R & - & 35,6 & - & - & - \\
\hline & V.1 & 0,38 & 26,1 & - & - & - \\
\hline & V.2 & 0,38 & 32,3 & - & - & - \\
\hline & V.3 & 0,38 & 42,6 & 5,30 & 6,04 & 87,8 \\
\hline \multirow[t]{2}{*}{ Oliveira, 2007} & V.1 & 0,00 & 47,0 & 5,18 & 5,91 & 87,6 \\
\hline & V.2 & 0,00 & 41,6 & 5,58 & 5,64 & 98,9 \\
\hline
\end{tabular}




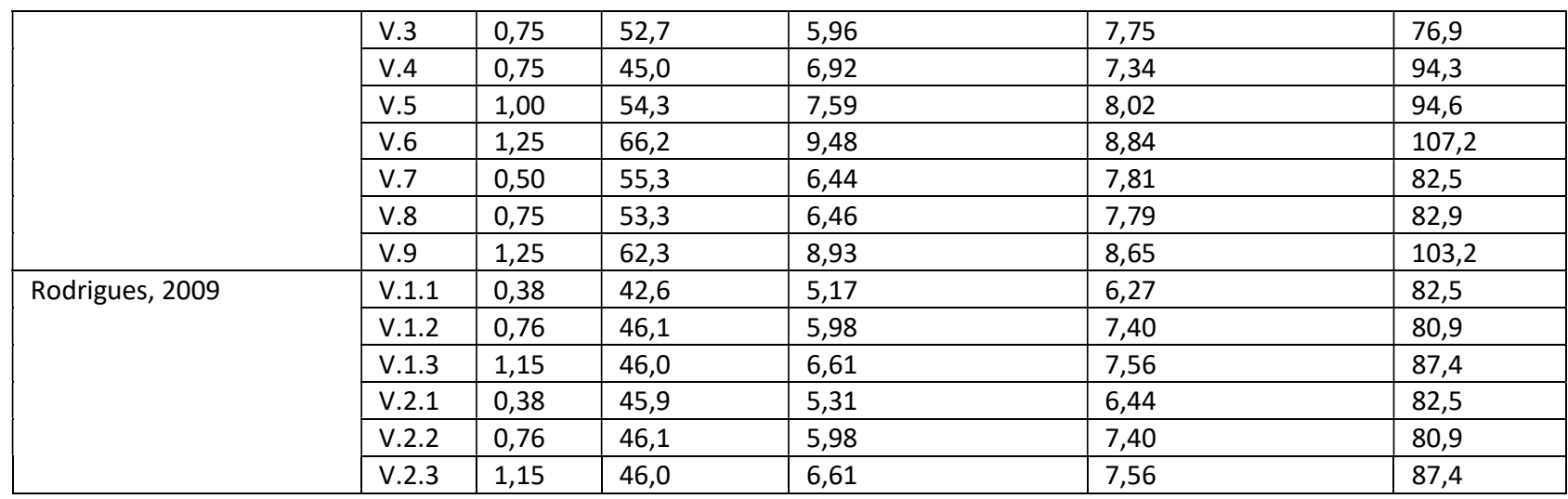

\section{Resistência a tração na flexão do concreto}

A resistência à flexão (tração na flexão) é uma propriedade mecânica dos concretos. Quando adiciona fibras dispersas na mistura do concreto ocorre um aumento significativo na resistência flexão, podendo alcançar aumentos maiores do que 100\% (OLIVEIRA, 2005). Alguns fatores podem influenciar no aumento de resistência de concreto com fibras, tais como o volume de fibras e o fator de forma (BENTUR et al., 2007).

A influência da resistência à flexão (tração na flexão) da adição de fibras em concretos e argamassas apresenta ganhos superiores em comparação com aqueles na compressão e na tração. A resistência a flexão é superior aos concretos com fibras, pois verifica-se uma alteração na distribuição de tensões e deformações, devido ao comportamento pseudodúctil do concreto (BENTUR et al., 2007; ACI 544. 1R-96, 2002). Segundo ACl 544 4R-88 (1999), são considerados dois valores de resistência à flexão, a relativa à carga fissuração (ponto $\mathrm{A}$ ) e a relativa à carga máxima alcançada (ponto $\mathrm{C}$ ), conforme demonstrado na Figura 9.

Existe uma relação linear entre resistências última e de fissuração e o volume de fibras e o fator de forma. Segundo Shah et al. (1971), citado por Bentur et al. (2007), propuseram a equação 2 para avaliar a resistência.

$$
f_{c t f, f}=A f_{c t, f}\left(1-V_{f}\right)+B\left(V_{f} L_{f} / D_{f}\right)
$$

onde:

$\mathrm{f}_{\mathrm{ctf}, \mathrm{f}}$ : Resistência do concreto com fibras à flexão, em Mpa; $\mathrm{f}_{\mathrm{ct}, \mathrm{f}}$ : Resistência à flexão do concreto sem a presença das fibras, em Mpa; A e B : Constantes determinadas empiricamente.

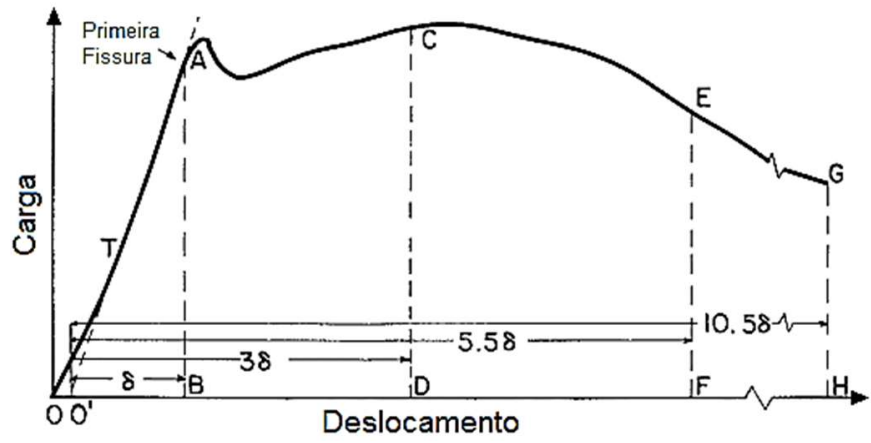

Figura 9: Principais características da curva carga-deslocamento. Fonte: ASTM C 1018 (1997).

De acordo com Oliveira (2005), as constantes A e B para os concretos sem fibras são respectivamente 1 e 0 . Sendo que a constante B considera a distribuição aleatória das fibras e a resistência da ligação entre as fibras e a matriz. Os valores experimentais de resistência à tração na flexão do concreto com ou sem fibras 
$\left(f_{c t, f}\right)$ foram obtidos por meio de materiais disponíveis em literatura. O cálculo teórico foi realizado a partir da equação 2, com os dados fornecidos pelos pesquisadores dos trabalhos analisados.

Oliveira (2007), realizou ensaios de flexão em prismas carregados com duas forças concentradas nos terços médios do vão. $O$ autor ensaiou diferentes geometrias de corpos de prova, as dimensões eram: 100 $\mathrm{mm} \times 100 \mathrm{~mm} \times 400 \mathrm{~mm}$ com vão de $300 \mathrm{~mm}, 150 \mathrm{~mm} \times 150 \mathrm{~mm}$ x $600 \mathrm{~mm}$ com vão de $450 \mathrm{~mm}$ e $200 \mathrm{~mm}$ x $200 \mathrm{~mm} \times 800 \mathrm{~mm}$ com vão de $600 \mathrm{~cm}$. Portanto, para obtenção do $f_{\mathrm{cf}, \mathrm{f}}$ de cada mistura de concreto, realizou a média dos corpos de provas. Alguns resultados demonstraram discrepância, por isso os valores que estavam acima e a baixo de $30 \%$ da média, foram desconsiderados deste estudo e calculado uma nova média de $f_{c t, f}$, conforme mostrado na Tabela 8.

Como não houve uma boa concordância entre os valores experimentais para um mesmo tamanho de corpos de prova, fica claro que a comparação da resistência à tração na flexão com uma expressão que não leva em conta a variação no tamanho da seção transversal, como a equação 2 , pode levar a erros consideráveis. A equação 2 leva em consideração um coeficiente de referência, sendo o fct,f de um corpo de prova sem fibras. Alguns pesquisadores não realizam ensaios de corpos de prova sem fibra, como no caso Rodrigues Jr. (2009), o que inviabiliza a comparação teórico-experimental. Esses resultados deixam clara a necessidade de um estudo mais aprofundado que permita a determinação de uma expressão para a avaliação da resistência à tração na flexão que leve em conta não apenas o tamanho dos corpos de prova, mas principalmente, possibilite a determinação de novos coeficientes para a expressão de Shah et al. (1971), citado por Bentur et al. (2007).

Tabela 8: Valores experimentais e teóricos da tração na flexão.

\begin{tabular}{|c|c|c|c|c|c|c|}
\hline Autor & $\mathbf{z}$ & Vigas & $V_{f}(\%)$ & $\mathbf{f}_{\mathrm{ct}, \mathrm{f}}(\mathrm{MPa})$ (Exp.) & $\mathbf{f}_{\mathrm{ctf}, \mathrm{f}}(\mathrm{MPa})$ (Calc.) & $f_{c t, f}(\%)$ \\
\hline \multirow[t]{9}{*}{ Oliveira, 2007} & & V.1 & 0 & 4,86 & 4,86 & 0,00 \\
\hline & & V.2 & 0 & 4,86 & 4,86 & 0,00 \\
\hline & & V.3 & 0,75 & 7,65 & 7,64 & 0,11 \\
\hline & & V.4 & 0,75 & 7,65 & 7,64 & 0,11 \\
\hline & & V.5 & 1,0 & 11,48 & 8,62 & 24,97 \\
\hline & & V.6 & 1,25 & 12,89 & 9,59 & 25,59 \\
\hline & & V.7 & 0,5 & 6,27 & 6,66 & 6,27 \\
\hline & & V.8 & 0,75 & 7,65 & 7,64 & 0,11 \\
\hline & & V.9 & 1,25 & 12,89 & 12,65 & 1,84 \\
\hline
\end{tabular}

\section{Comportamento das vigas a flexão}

De acordo com as recomendações do ACI 544.4R - 88 (1999), para aplicações estruturais, a utilização das fibras de aço deve ser feita concomitantemente com as barras de aço convencionais de tração, ou seja, as fibras de aço devem ter um papel secundário no reforço da estrutura, como, por exemplo, inibir a fissuração e melhorar a resistência ao impacto ou carregamentos dinâmicos. Em outras palavras, em elementos estruturais onde ocorrerá flexão ou atuarão carregamentos que induzam tensões de tração, as barras da armadura principal deverão ser capazes de resistir, na sua totalidade, aos esforços resultantes, mesmo na situação onde se faz uso do concreto com fibras de aço. Ainda segundo o ACI 544.4R (1998), essas restrições se devem à variabilidade na distribuição das fibras, que pode ser de tal forma que cause uma baixa quantidade de fibras em áreas críticas, ocasionando inaceitáveis reduções na resistência. O levantamento realizado proporcionou na elaboração da Figura 10 e Tabela 9, em que é apresentado $M_{u}$ (momento último) 
com ou sem fibras em relação ao teor de fibras em volume e na tabela momento último em relação ao $\delta_{u}$ (deslocamento vertical relativo a carga última).

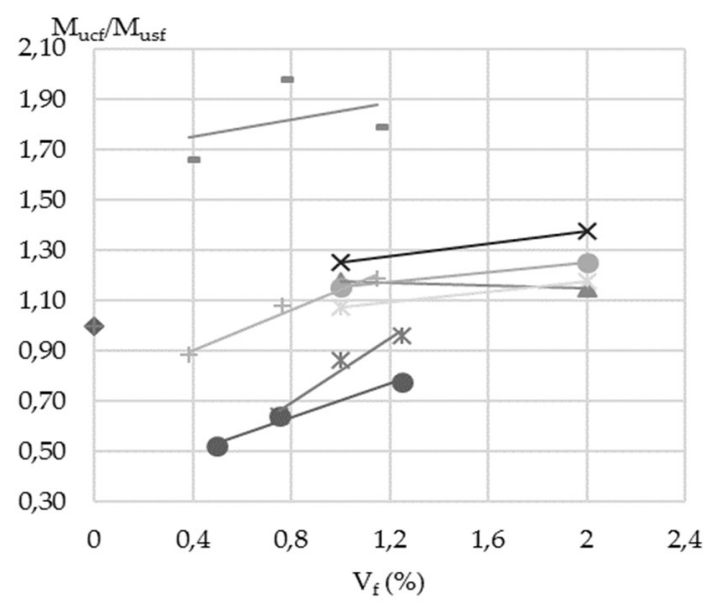

$\triangle$ FURLAN e HANAI - (Aço 25,4mm-A)

$\times$ FURLAN e HANAI - (Aço 25,4mm-B)

FURLAN e HANAI - (Aço 38,1mm-A)

- FURLAN e HANAI - (Aço 38,1mm-B)

* OLIVEIRA, 2007 (Aço arm. 2)

- OLIVEIRA, 2007 (Aço arm. 3)

+ RODRIGUES JR. (2009) (arm. 1)

- RODRIGUES JR. (2009) (arm. 2)

+ FURLAN e HANAI - (sem fibra B)

Figura 10: Comparação das Curvas momento-deslocamento último em vigas de concreto. Legenda: *Mucf: Momento útil com fibra; *Musf: Momento útil sem fibra.

Tabela 9: Valores experimentais momento último e deslocamento vertical relativo à carga última.

\begin{tabular}{|c|c|c|c|c|c|c|}
\hline Autor & Vigas & $\mathrm{Vf}(\%)$ & $\mathrm{Mu}$ (kN.m) & $\delta u(m)$ & $\mathrm{Mu}(\%)$ & $\delta u(\%)$ \\
\hline \multirow[t]{12}{*}{ Furlan et al., 1997} & V.1. A & 0,00 & 4,80 & 0,0110 & - & - \\
\hline & V.3.A & 0,33 & 7,05 & 0,0175 & 46,8 & 59,1 \\
\hline & V.4.A & 0,66 & 6,90 & 0,0250 & 43,7 & 127,2 \\
\hline & V.5.A & 0,33 & 6,45 & 0,0280 & 34,3 & 154,5 \\
\hline & V.6.A & 1,00 & 7,05 & 0,0235 & 46,8 & 113,6 \\
\hline & V.7.A & 0,25 & 6,75 & 0,0140 & 40,6 & 27,3 \\
\hline & V.1. B & 0,00 & 6,78 & 0,0070 & - & - \\
\hline & V.3.B & 0,33 & 6,00 & 0,0056 & 11,5 & 20,0 \\
\hline & V.4.B & 0,66 & 6,6 & 0,0120 & 10,0 & 71,4 \\
\hline & V.5.B & 0,33 & 5,55 & 0,0045 & 15,9 & 35,7 \\
\hline & V.6.B & 1,00 & 6,00 & 0,0075 & 8,1 & 7,1 \\
\hline & V.7.B & 0,25 & 5,25 & 0,0045 & 12,5 & 35,7 \\
\hline \multirow[t]{4}{*}{ Oliveira, 2005} & V.R & 0 & 6,36 & 0,0009 & - & - \\
\hline & V.1 & 0,38 & 8,80 & 0,0140 & 38,3 & 15,4 \\
\hline & V.2 & 0,38 & 10,96 & 0,0221 & 72,3 & 25,0 \\
\hline & V.3 & 0,38 & 14,12 & 0,0346 & 122,0 & 39,7 \\
\hline \multirow[t]{4}{*}{ Lobão, 2005} & V.R & 0 & 4,52 & 0,0009 & - & - \\
\hline & V.1 & 0,38 & 5,40 & 0,0083 & 19,5 & 8,2 \\
\hline & V.2 & 0,38 & 8,28 & 0,0226 & 83,2 & 24,2 \\
\hline & V.3 & 0,38 & 1,04 & 0,0234 & 76,9 & 25,0 \\
\hline \multirow[t]{9}{*}{ Oliveira, 2007} & V.1 & 0 & 161,03 & 0,0969 & - & - \\
\hline & V.2 & 0 & 109,21 & 0,0502 & - & - \\
\hline & V.3 & 0,75 & 92,23 & 0,0076 & - & - \\
\hline & V.4 & 0,75 & 70,13 & 0,0049 & - & - \\
\hline & V.5 & 1 & 94,50 & 0,0052 & 34,7 & 7,0 \\
\hline & V.6 & 1,25 & 105,16 & 0,0059 & 49,9 & 21,6 \\
\hline & V.7 & 0,5 & 83,91 & 0,0062 & - & - \\
\hline & V.8 & 0,75 & 103,66 & 0,0097 & 23,5 & 57,0 \\
\hline & V.9 & 1,25 & 125,33 & 0,0094 & 49,3 & 52,2 \\
\hline \multirow[t]{6}{*}{ Rodrigues 2007} & V.1.1 & 0,38 & 22,08 & 0,0192 & - & - \\
\hline & V.1.2 & 0,76 & 26,96 & 0,0153 & 22,1 & 20,3 \\
\hline & V.1.3 & 1,15 & 29,68 & 0,0141 & 34,4 & 26,5 \\
\hline & V.2.1 & 0,38 & 41,60 & 0,0340 & - & - \\
\hline & V.2.2 & 0,76 & 49,44 & 0,0276 & 18,8 & 18,8 \\
\hline & V.2.3 & 1,15 & 44,80 & 0,0206 & 7,6 & 39,4 \\
\hline
\end{tabular}

Observando os valores da Tabela 9, verifica-se que os valores do Mu (momento último) e $\delta u$ (deslocamento vertical relativo a carga última) das vigas de concreto não se aproximam dos valores da viga 
de referência, com diferenças significativas dependendo do autor. Essa diferença é devida ao acréscimo de fibras na mistura da matrix de concreto, confirmado pela Figura 10. Portanto, a adição de fibras de aço proporcionou aumento no momento último e no deslocamento vertical último em vigas de concreto com armadura, sendo que, quanto maior a resistência à tração das fibras de aço, maior o momento último.

Desta forma, as fibras podem ser uma solução interessante quando se objetiva melhorar o desempenho das estruturas de concreto. $\mathrm{O}$ ganho no $\mathrm{Mu}$ (momento último) e $\delta u$ (deslocamento vertical relativo a carga última) que as fibras proporcionam pode, eventualmente, possibilitar elementos mais esbeltos e a armadura mínima para controle de fissuras, maior que aquela que visa evitar ruptura frágil quando da fissuração.

\section{CONCLUSÕES}

As propriedades mecânicas do concreto com fibras dependem do volume de fibra a ser utilizado e das propriedades da matriz de concreto. Entretanto, de um modo geral, ao adicionar fibras ao concreto, a resistências mecânicas do compósito podiam ser aumentadas substancialmente, porém o estudo teóricoexperimental mostrou que com o volume e os tamanhos de fibras que poderiam ser convenientes incorporados a argamassas e concretos convencionais, os concretos com fibras em alguns casos não apresentam melhoria significante nas propriedades mecânicas, podendo ter até ter redução na resistência a compressão.

Pesquisadores apontam que as fibras adicionadas ao concreto convencional ocasionam uma melhoria no comportamento pós-fissuração e na ductilidade. Sendo que a propriedade mais importante dos concretos com fibras é o impedimento da propagação de fissuras. Visto que nesta pesquisa não foi avaliado nenhuma destas propriedades.

A importância do estudo sistemático envolvendo vigas com diferentes dimensões, diâmetros e taxas de armadura, tipos e teores de fibras e resistências do concreto possibilitarão compreender melhor essa interação e os parâmetros principais que definem a contribuição das fibras na resistência à compressão, compressão diametral, tração na flexão e flexão em vigas. Essa compreensão é importante pois permite que estudos de vigas de concreto armado com fibras de aço, possa utilizar equações como substituição parcial ou total de alguns ensaios, o que trará enorme vantagem de ordem prática.

$\mathrm{O}$ avanço das pesquisas acerca das propriedades do concreto com fibras, tende a melhorar o desempenho desse material e abrir novos campos de aplicação. Para isso, é necessário que ocorra um aperfeiçoamento nos métodos de análise, levando em consideração todos os parâmetros existentes, permitindo uma coerência entre os valores experimentais e teóricos.

AGRADECIMENTOS: Ao Instituto Militar de Engenharia (IME) e à Coordenação de Aperfeiçoamento Pessoal de Nível Superior - CAPES, pelo apoio prestado para a realização desta pesquisa. 


\section{REFERÊNCIAS}

ALBERTI, M. G.; ENFADAQUE, A.; GÁLVEZ, J. C.. Hormigón autocompactante reforzado simultáneamente con fibras estructurales de poliolefina y conformadas de acero. Revista Técnica Cemento Hormigón, n.963, p.8-15, 2014.

ASTM. American Society for Testing and Material. ASTM C1018 - 97: Standard test method for flexural toughness and first-crack strength of fiber reinforced concrete (using beam with third-point loading). Annual Book of ASTM, 1997.

ACl. American Concrete Institute. ACI 544. 4R-88: Design considerations for steel fiber reinforced concrete. In: Manual of concrete practice. Detroit, 1999.

ACl. American Concrete Institute. ACI 544. 2R-89:.

Measurement of properties of fiber reinforced concrete. In: Manual of concrete practice. Detroit, 2009.

ACl. American Concrete Institute. ACI 544. 1R-96. State-ofthe-art report on fiber reinforced concrete. In: Manual of concrete practice: part 5. ACI Committee 544. Detroit, 2002.

ABNT. Associação Brasileira de Normas Técnicas. NBR 5739: Concreto - Ensaio de compressão de corpos de prova cilíndricos. Brasília, 2007.

BALAGURU, P. N.; SHA, S. P.. Fiber Reinforced Cement Compósites. New York: McGraw-Hill. 1992.

BENTUR, A.; MINDESS, S.. Fibre Reinforced Cementitious Composites. 2 ed. Taylor \& Francis, London and New York, 2007.

FIGUEIREDO, A. D.. Concreto com fibras de aço: Boletim Técnico (BT/PCC/260). São Paulo: Escola Politécnica da Universidade de São Paulo, 2000.

FIGUEIREDO, A. D.. Concreto Reforçado com Fibras. Tese (Doutorado) - Universidade de São Paulo, São Paulo, 2011.

FURLAN Jr, S.; HANAI, J. B.. Shear Behaviour of Fiber Reinforced Concrete Beams. Cement and concrete composites, v.19, n.4, p.359-366, 1997.
IMAM, M.; VANDEALLE, L.; MORTELMANS, F.. Shear moment analysis of reinforced high strength concrete beams containing steel fibres. Canadian Journal of Civil Engineering, v.22, n.3, p.462-470, 1995.

LOBÃO, L. M. M.. Taxa de armadura longidutinal de tração minima em vigas de concreto de resistência normal com fibras de aço. Dissertação (Mestrado) - Universidade Federal do Rio de Janeiro, Rio de Janeiro, 2005.

LOPES, M. M.. Substituição parcial de armadura de flexão por fibras de aço em vigas de concreto. Dissertação (Mestrado) - Universidade Federal do Rio de Janeiro, Rio de Janeiro, 2005.

NAAMAN, A. E.. High performance fiber reinforced cement composites: classification and applications. In: $\mathrm{CBM}-\mathrm{Cl}$ INTERNATIONAL WORKSHOP. Anais. Karachi, 2007. p.389401.

NEVILLE, A. M.; BROOKS, J. J.. Tecnologia do concreto. 2 ed. Porto Alegre: Bookman, 2013.

OLIVEIRA, C. A. S.. Avaliação da redução de armadura mínima de flexão em vigas de concreto armado com adição de fibras de aço. Dissertação (Mestrado) - Universidade Federal de Goiás, Goiás, 2007.

OLIVEIRA, S. L.. Taxa de armadura longitudinal mínima em vigas de concreto de alta resistência com fibras de aço. Dissertação (Mestrado) - Universidade Federal do Rio de Janeiro, Rio de Janeiro, 2005.

RODRIGUES Jr., A.. Comportamento de vigas de concreto com fibras e baixas taxas de armadura longitudinal. Dissertação (Mestrado) - Universidade Federal do Rio de Janeiro, Rio de Janeiro, 2009.

SALVADOR, R. P.. Análise comparativa de métodos de ensaio para caracterização do comportamento mecânico de concreto reforçado com fibras. Dissertação (Mestrado) Escola Politécnica da Universidade de São Paulo, São Paulo, 2013.

ZIA, P.; AHMAD, S.; LEMING, M.. State of the art report: high performance concrete. McLean: Federal Highway Administration, 1994.

A CBPC - Companhia Brasileira de Produção Científica (CNPJ: 11.221.422/0001-03) detém os direitos materiais desta publicação. Os direitos referem-se à publicação do trabalho em qualquer parte do mundo, incluindo os direitos às renovações, expansões e disseminações da contribuição, bem como outros direitos subsidiários. Todos os trabalhos publicados eletronicamente poderão posteriormente ser publicados em coletâneas impressas sob coordenação da Sustenere Publishing, da Companhia Brasileira de Produção Científica e seus parceiros autorizados. Os (as) autores (as) preservam os direitos autorais, mas não têm permissão para a publicação da contribuição em outro meio, impresso ou digital, em português ou em tradução. 